Original Article

\title{
AN INVITRO COM PARATIVE EVALUATION OF FRACTURE RESISTANCE OF ENDODONTICALIY TREATED TEETH OBTURATED WITH RESILON AND GUTTA-PERCHA
}

\author{
Kiran Halkai ${ }^{1}$, Rahul Halkai', Mithra N. Hegde ${ }^{3}$, Vijay Kumar ${ }^{4} \&$ Arpita $^{5}$ \\ ${ }^{1}$ Senior Lecturer, Department of Conservative Dentistry \& Endodontics, SN HKE Dental College, Gulbarga. \\ ${ }^{2}$ Ph.D Student, ${ }^{3}$ Senior Professor \& HOD, Department of Conservative \& Endodontics, A.B. Shetty M emorial Institute of \\ Dental Sciences, Nitte University, M angalore - 575 018, Karnataka. ${ }^{4,5}$ Senior Lecturers, Department of Community \\ Dentistry, M.N.R. Dental College, Sangareddy, Andhra Pradesh, India. \\ Correspondence : \\ Kiran Halkai \\ Senior Lecturer, SN HKE Dental College, Gulbarga. \\ Mobile : +91 7204166552 E-mail : drkiranc_15@yahoo.com
}

\begin{abstract}
:
Aim: To compare and evaluate in-vitro the fracture resistance of endodontically treated teeth obturated with resilon \& epiphany sealer and guttapercha using different sealers. Epoxy resin based sealer AH-plus and zinc oxide eugenol based sealer-TubliSeal (EWT).

Methodology : sixty four human single rooted maxillary anterior teeth, cleaned stored in $0.9 \%$ saline. All the teeth were decoronated to root length $14 \mathrm{~mm}$ and bucco-lingual diameter of $5-7 \mathrm{~mm}$, After access openings teeth were instrumented using $\mathrm{K} 3.06$ up to final apical size 30/.06 and randomly allocated into 4 experimental groups ( $n=16$ per group). Group 1(Control group): teeth were instrumented but not obturated, Group 2: Resilon cones and epiphany SE-sealer. Group 3: guttapercha cones and epoxy based sealer AH plus. Group 4: guttapercha and Tubli seal EWT. Coronal seal was done using IRM cement. Each of the specimens were tested for fracture resistance by instron universal testing machine.
\end{abstract}

Results: Higher fracture resistance values were observed for group 2 (Resilon \& Epiphany SE sealer) followed by group 3(Guttapercha \& AH Plus sealer) and group 4(Guttapercha \& TubliSeal EWT) when compared to group 1 (control-instrumented but not obturated).

Conclusion: filling the root canals with contemporary polymer based root canal obturating system- Resilon increased the in vitro fracture resistance of endodontically treated teeth.

Keywords : Fracture resistance, resilon, guttapercha.

\section{Introduction :}

Endodontically treated teeth are widely considered to be more susceptible to fracture than the vital teeth. The reasons most often reported have been the loss of structural integrity ${ }^{1}$, loss of collagen cross-linking and water loss ${ }^{2}$, dehydration of the dentine after endodontic therapy, removal of tooth structure during several endodontic procedures ${ }^{3}$, such as access cavity preparation,

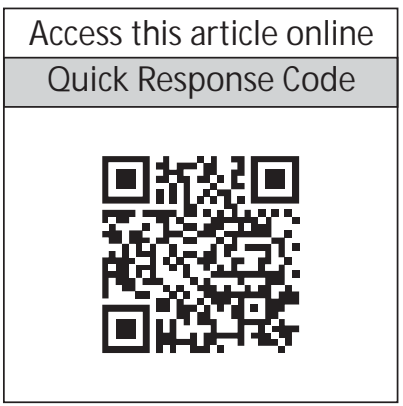

cleaning \& shaping, root canal irrigation ${ }^{4}$, and excessive pressure during obturation ${ }^{5}$. It is commonly believed that the loss of dentine results in an increased susceptibility to fracture ${ }^{6}$.
Obturation of the root canal system is an important step for the success of endodontically treated teeth. Currently, there are a plethora of materials and condensation techniques available that must meet the basic requirements of obturation phase. Guttapercha with a root canal sealer has widely been used for years as a root canal filling material due to its biocompatibility, dimensional stability, thermoplasticity, and ease of removal. But, its limited ability to fill and seal the root canal system has been reported for the majority of root canal failures. However, despite of their limited ability to achieve an impervious seal along the dentinal walls of the root canal, it remains the material of choice against which the other obturating materials are compared ${ }^{7}$.

Root canal sealers should strongly adhere to dentine. 
Increased adhesiveness to dentine may lead to greater strength of the restored teeth, which may provide greater resistance to tooth fracture and clinical longitivity of an endodontically treated tooth and therefore, decreasing the chances of endodontic failure ${ }^{8}$

Although few materials have seriously challenged guttapercha and sealer in majority of filling situations, research continues to find alternatives that may seal better and mechanically reinforce compromised roots. Resin based sealers have been used for several years to take advantage of adhesion to the dentinal walls which results in less micro leakage and is considered to provide some strengthening effect to the teeth. ${ }^{9}$

Resilon a synthetic polymer based obturating material broadens the dimensions of endodontic adhesion. This system consists of a combination of primer, dual cure sealer and resin obturating material ${ }^{16}$ and creates a monoblock filling. This is created by the adhesion of resilon cone to resin based sealer, which adheres to the dentinal wall and penetrates into dentinal tubules. ${ }^{10,11}$ Shipper et al called it as "Resilon Monoblock system" (RMS), which has the potential to strengthen the root canal walls against the fracture and decrease the micro leakage.

The purpose of this in-vitro study was to compare the fracture resistance of endodontically treated teeth obturated with Resilon \& Epiphany SE sealer with that of conventional Guttapercha using different sealers Epoxy resin based sealer-AH Plus and Zinc oxide Eugenol based sealer-TubliSeal EWT.

\section{Methodology:}

Sixty four human single rooted maxillary anterior teeth recently extracted for periodontal reasons, root length of at least $14 \mathrm{~mm}$ and bucco-lingual dimensions of $5-7 \mathrm{~mm}$ confirmed with the help of digital Vernier callipers were used. Examined under 20x magnification under a microscope to rule out any cracks, caries, and fractures or craze lines and radiographed to determine the presence of a single canal were included for the present study. The teeth were cleaned off soft tissue, calculus and stains with the help of sharp hand scalers thoroughly washed and stored in $0.9 \%$ saline at room temperature until use.

All the teeth specimens were decoronated using a double sided diamond coated disc, so that the remaining root length was $14 \mathrm{~mm}$ and the bucco-lingual diameter of $5-7 \mathrm{~mm}$. In all the 64 specimens access openings were prepared using \#4 round bur and working length was determined by placing a No $10 \mathrm{~K}$ file (M ani) in to the root canal, until it was just visible at the apical foramen and then withdrawing it by $1 \mathrm{~mm}$. The teeth were instrumented using K3 .06 (SybronEndo, USA) Ni-Ti rotary instrument system in an Anthogyr gear reduction hand piece (Dentsply) at $250 \mathrm{rpm}$ using a gentle in and out motion, to final apical size 30/.06.

Copious root canal irrigation using $5 \mathrm{ml}$ of $3 \%$ sodium hypochlorite solution using a syringe and 27 gauge needle was performed finally flushed with $5 \mathrm{ml}$ of $17 \%$ EDTA solution followed by $5 \mathrm{ml}$ of $3 \%$ sodium hypochlorite solution in order to remove the smear layer for 1-2 minutes. This was followed by a final irrigation with $5 \mathrm{ml}$ of $0.9 \%$ Normal saline. Each of the root canal specimens were dried with sterile paper points.

All the 64 specimens were randomly allocated into 4 experimental groups ( $n=16$ per group) asfollows.

Group 1: (Control group) teeth were instrumented but not obturated.

Group 2: Obturation was done using resilon cones and epiphany SE sealer.

Group 3: Obturation was done using guttapercha and $\mathrm{AH}$ plus

Group 4: Obturation was done using guttapercha cones and tubli seal EWT.

In all the groups the specimens were obturated using lateral condensation technique, the sealers were mixed according to the manufacturer's instructions and applied using lentulo spirals. Finally $1 \mathrm{~mm}$ coronal seal was done using IRM cement.

\section{Preparation for mechanical testing:}

An acrylic block was fabricated to allow for adequate 
stabilization of the specimens during testing procedures. A $20 \times 20 \times 25 \mathrm{~mm}$ aluminium mould was used. Self curing acrylic resin was introduced in to the mould in dough stage and then root ends were embedded in to resin in a vertical plane and long axis of each root was vertically aligned using a protractor. Later on the acrylic blocks were polished and allowed to set at room temperature. IRM cement is removed using carbide bur and each of the specimens were tested for fracture resistance by Instron Universal testing machine.

Each of the mounted specimens was placed on a metal base under the Instron universal testing machine. A spherical tip of radius $2 \mathrm{~mm}$ was used to apply a vertical loading force at a cross head speed of $1 \mathrm{~mm}$ per minute until fracture occurred. Fracture resistance was defined as the point at which a sharp decline and instantaneous drop greater than $25 \%$ of the applied load was observed for each root and so the machine was adjusted to terminate the test when a $25 \%$ reduction of force applied was observed. At that time the maximum force to fracture the specimen was recorded.

The loads at which different root specimens fractured were recorded in Newton's and the data was subjected to appropriate statistical analysis (table 1).

\section{RESULTS:}

Data were summarized as Mean $\pm \mathrm{SD}$. Considering this statistical situation a more detailed analysis One Way ANOVA test was done (table 2). Further this was substantiated with multiple comparisons through Post hoc Scheffe multiple comparison test (table 3). The following results were drawn from the study.

I Higher fracture resistance values were observed for group 2 (Resilon \& Epiphany SE sealer) followed by group 3(Guttapercha \& AH Plus sealer) and group 4(Guttapercha \& TubliSeal EWT) when compared to group1 (control-instrumented but not obturated).

I Significant difference between group 1 and group 2, Group 1\& group 3.

I However there was no significant difference between group 1 and group 4.

I Group 2 compared to group 1 and group 4 showed highly significant difference.

I Group 3 showed significant difference when compared to group 1 and group 4.

I No Statistically significant difference was observed between group 2 and group 3.

I Similarly no statistical difference was observed between group 1 and group 4.

Table 1: Descriptive statistics of the loads to fracture different specimens.

\begin{tabular}{|l|c|c|c|c|c|c|}
\hline Group & No. & $\begin{array}{c}\text { Minimum } \\
\text { Load }\end{array}$ & $\begin{array}{c}\text { Maximum } \\
\text { Load }\end{array}$ & Mean & $\begin{array}{c}\text { Standard } \\
\text { deviation }\end{array}$ & $\begin{array}{c}\text { Std. Error } \\
\text { of mean }\end{array}$ \\
\hline $\begin{array}{l}\text { Group 1 } \\
\text { Control }\end{array}$ & 16 & 173.83 & 263.01 & 215.2975 & 22.74279 & 5.77497 \\
\hline $\begin{array}{l}\text { Group 2 } \\
\text { Resilon }\end{array}$ & 16 & 344.67 & 447.95 & 399.5850 & 27.65964 & 6.66491 \\
\hline $\begin{array}{l}\text { Group 3 } \\
\text { AH Plus }\end{array}$ & 16 & 346.12 & 434.78 & 378.8906 & 25.94616 & 6.48654 \\
\hline $\begin{array}{l}\text { Group 4 } \\
\text { Tubliseal EWT }\end{array}$ & 16 & 193.58 & 284.75 & 224.7513 & 23.09989 & 5.68570 \\
\hline
\end{tabular}

Table 2 : One Way-ANOVA Analysis

\begin{tabular}{|l|c|c|c|c|c|}
\hline $\begin{array}{l}\text { ANOVA } \\
\text { Dependent } \\
\text { Variable }\end{array}$ & $\begin{array}{c}\text { Sum of } \\
\text { squares }\end{array}$ & $\begin{array}{c}\text { Degree of } \\
\text { freedom }\end{array}$ & $\begin{array}{c}\text { Mean } \\
\text { squares }\end{array}$ & Fvalue & Significance \\
\hline Between groups & 508933.5 & 3 & 69644.511 & 78.702 & .000 \\
\hline Within groups & 36521.686 & 60 & 608.695 & & \\
\hline Total & 545455.2 & 63 & & & \\
\hline
\end{tabular}

F value - 278.702

ANOVA revealed very highly significant difference between the groups i.e., $P \varangle 0.001$. 
Table 3 : Post Hoc Scheffe multiple comparison tests for comparing the fracture loads of specimens of several test groups.

\begin{tabular}{|c|c|c|c|c|c|c|}
\hline \multirow{2}{*}{$\begin{array}{l}\text { ( I) Type Of } \\
\text { Material } \\
\text { (groups) }\end{array}$} & \multirow{2}{*}{$\begin{array}{l}\text { (J) Type Of } \\
\text { Material }\end{array}$} & \multirow[t]{2}{*}{ Mean Diff. (I-J) } & \multirow[t]{2}{*}{ Std. Error } & \multirow[t]{2}{*}{ Sig. } & \multicolumn{2}{|c|}{$\mathbf{9 5 \%}$ confidence interval } \\
\hline & & & & & $\begin{array}{c}\text { Lower } \\
\text { boundary }\end{array}$ & $\begin{array}{c}\text { Upper } \\
\text { boundary }\end{array}$ \\
\hline \multirow{3}{*}{$\begin{array}{l}\text { Control } \\
\text { (Group1) }\end{array}$} & Resilon & $-184.28750 *$ & 8.72278 & .000 & -209.3785 & -159.1965 \\
\hline & AH Plus & $-181.59313^{*}$ & 8.72278 & .000 & -206.6842 & -156.5021 \\
\hline & Tubliseal EWT & -9.45375 & 8.72278 & .760 & -34.5448 & 15.6373 \\
\hline \multirow{3}{*}{$\begin{array}{l}\text { Resilon } \\
\text { (Group2) }\end{array}$} & Control & 184.28750* & 8.72278 & .000 & 159.1965 & 209.3785 \\
\hline & AH Plus & 2.69438 & 8.72278 & .867 & -22.3967 & 27.7854 \\
\hline & Tubliseal EWT & 174.83375* & 8.72278 & .000 & 149.7427 & 199.9248 \\
\hline \multirow{3}{*}{$\begin{array}{l}\text { AH Plus } \\
\text { (Group3) }\end{array}$} & Control & 181.59313* & 8.72278 & .000 & 156.5021 & 206.6842 \\
\hline & Resilon & -2.69438 & 8.72278 & .867 & -27.7854 & 22.3967 \\
\hline & Tubliseal EWT & 172.13938* & 8.72278 & .000 & 147.0483 & 197.2304 \\
\hline \multirow{3}{*}{$\begin{array}{l}\text { Tubliseal EWT } \\
\text { (Group4) }\end{array}$} & Control & 9.45375 & 8.72278 & .760 & -15.6373 & 34.5448 \\
\hline & Resilon & $-174.83375^{*}$ & 8.72278 & .000 & -199.9248 & 149.7427 \\
\hline & AH Plus & -172.13938* & 8.72278 & .000 & -197.2304 & -147.0483 \\
\hline
\end{tabular}

$*$ The mean difference is significant at the .05 level.

Dependent Variable (Force Newton)

Graph 1: Graphical representation of the mean load values to fracture roots.

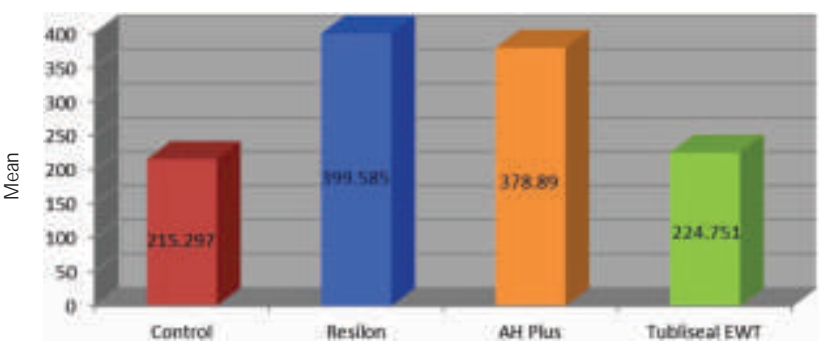

Graph 3: Pattern of fractures in different root specimens

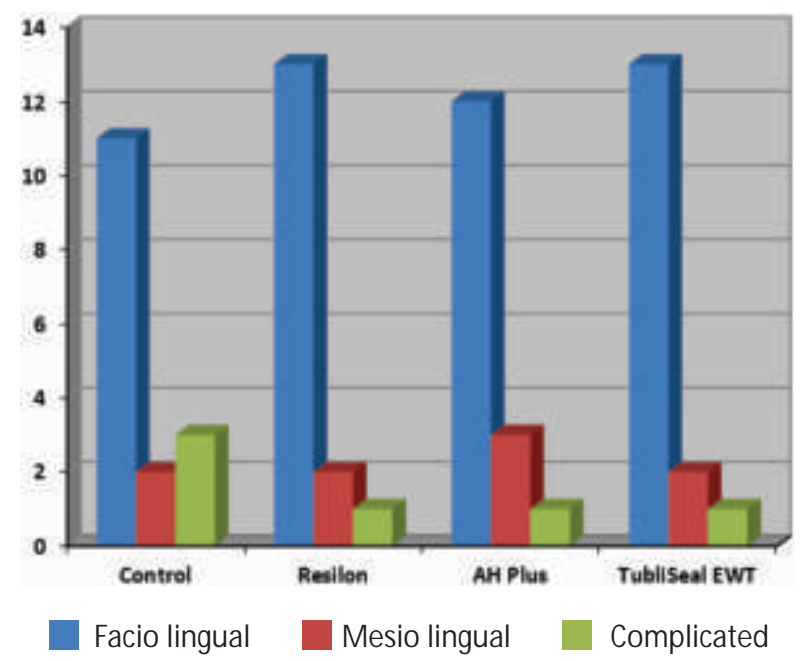

\section{Discussion:}

Root canal instrumentation is an essential stage in endodontic treatment. There is a perception that endodontic treatment weakens the tooth structure and predisposes teeth to fracture ${ }^{2,3,4,5,6}$. Studies have suggested
Graph 2: Graphical representation of the mean standard deviation values to fracture

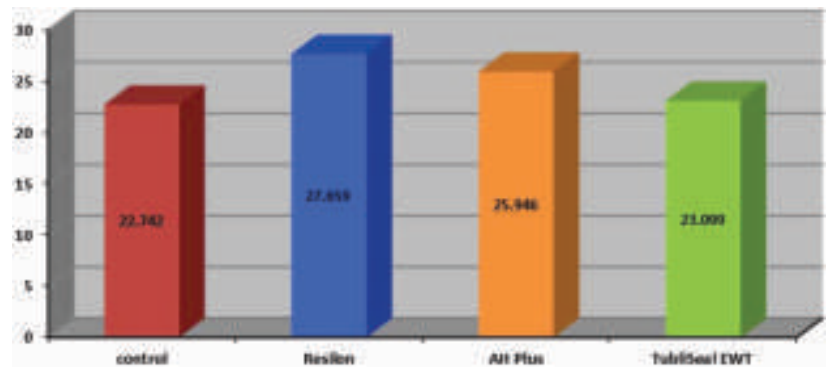

that as removal of tooth structure increases, fracture resistance of the tooth decreases. ${ }^{3,7}$ It has been reported that incidence of vertical root fractures is greater in root filled teeth than in the vital teeth. ${ }^{7,9,10,11}$ Addition of wedging forces of the spreader during lateral condensation or excessive removal of dentin to facilitate pluggers for vertical condensation, enhance the potential for root fracture ${ }^{1.5}$ Any material that can compensate for this weakening effect would be useful. ${ }^{1,6}$

The primary goal of endodontics is not only to treat the diseased pulp of a tooth, but also to increase the inherent strength of the remaining tooth structure. Resilon a synthetic polymer based obturating system has been claimed to be the most promising material as an alternative to guttapercha. Clinically, resilon appears similar to guttapercha and has the same handling characteristics, biocompatible, radio-opaque, dimensionally stable and 
has good flow properties, ${ }^{12}$ easily retrievable if needed ${ }^{13}$, can be utilized in various obturation techniques such as lateral condensation, vertical condensation and thermo plasticized techniques, ${ }^{14}$ it forms a superior seal to coronal \& apical leakage when compared with guttapercha techniques.

In the present study, root canal obturation was done by lateral condensation technique because it is a more widely recommended and a proven classic technique ${ }^{15}$

From the results of the present study, it was noticed that majority of the test specimens fractured in faciolingual directions which is in accordance to Lertchirakarn et al $(2002)^{16}$.

The development of bonded obturating materials is in congruence with the efforts to provide a more effective seal apically as well as coronally. The adhesion between dental structures and resin based sealers is the result of a physicochemical interaction across the interface, allowing the union between filling material, sealer and root canal wall. Because the resin core, sealant and the dentinal wall all are "attached", it appears logical that they have the potential to strengthen the walls against fracture. ${ }^{12}$

The fracture resistance of the specimens in group1

\section{References:}

1. Cohen S, Burns R. Pathways of Pulp. $8^{\text {th }}$ edi. St Louis: M osby; 2002.

2. Holcomb J Q, Pilts D, Nicholls J I. Further investigation of spreader loads required to cause vertical root fracture during lateral condensation. J Endod 1987; 13: 277-84.

3. Helfer AR, M elnickS, Schilder H. Determination of moisture content of vital and pulpless teeth. Oral surg Oral M ed Oral Pathol 1972; 34: 66170

4. Lewinstein L, Grajower R. Root dentin hardness of endodontically treated teeth..J Endod 1981; 7(4); 151-5.

5. Sim TPC, Knowles JC, Shelton J, Gulabivala K. Effect of sodium hypochlorite on mechanical properties of dentine and tooth surface strain. Int Endod J 2001;34:120-32.

6. Saw LH,M esser HH. Root strains associated with different obturation techniques.J Endod 1995;21:314-20.

7. Kishen A. Mechanisms and risk factors for fracture predilection in endodontically treated teeth. Endod Topics 2006;13(1):57-78

8. Hammed M, Qualtrough A, Silikas N. Effect of new obturating materials on vertical root fracture resistance of endodontically treated teeth JOE 2007;33(6): 732-736.

9. Whitworth J. Methods of filling root canals: Principles and practices. Endo Topics 2005;12(2):2-24.

10. Schafer $E$, Olthoff $G$. Effect of Three different sealers on the sealing (control) which were instrumented but not obturated was the least compared to all other groups with obturation. However clinically one can never leave an empty canal, but it suggests that the roots after endodontic treatment without any filling materials are not strong enough and have lower mean fracture resistance values and so in other words, all the filling materials appeared to strengthen the roots. ${ }^{10,12}$ According to the present study the comparison between Resilon and guttapercha groups showed highly statistically significant difference indicating that the monoblock concept is important not only to resist the microleakage through the material but also to hold the roots together, thereby increasing the resistance to fracture. ${ }^{7,10,12}$

\section{Conclusion:}

Based on the methodology and within the limitations of the present study finally it can be concluded that filling the root canals with contemporary polymer based root canal obturating system-resilon increased the in vitro fracture resistance of endodontically treated teeth. However additional in-vivo, in-vitro tests and clinical long term studies are desirable in order to elucidate the effectiveness and confident use of this material.

ability of both thermafil obturators and cold laterally compacted Gutta- percha Endod 2002;28: 423-6.

11. M onaghan P,Bajalcaliev JG, Kaminski EJ, Lautenschlager EP. A method for producing experimental simple vertical root fractures in dog teeth. J Endod 1993;19;512-5

12. Epiphany soft resin Endodontic obturation system manufacturer's instruction hand book. Pentron Clinical technologies LLC. Wallingford CT.

13. Weis MV, Parashos P, M esser HH. Effect of obturation technique on sealer cement thickness and dentinal tubule penetration. Int Endod J 2004;37:653-63.

14. Williams $C^{1}$, Loushine RJ, Weller RN, Pashley DH, Tay FR.A comparision of cohesive strength and stiffness of Resilon and gutta percha. J Endod 2006; 32(6):553-5.

15. Apicella MJ, Loushine RJ, West LA, Runyan DA. A comparision of root fracture resistance using two root canal sealers. Oral Surg Oral Med Oral Pathol Oral Radiol Endod 1999; 89:376-80

16) Greene HA, Wong $M$ and Ingram TA. Comparision of the sealing ability of four obturation techniques.J Endod 1990;16(9):423-28.

17. Texieira FB, Texieira EC, Thompson JY, Trope M. Fracture resistance of roots endodontically treated with a new resin filling material. J Am Dent Assoc. 2004; 135(5):646-52. 